\section{THE INFLUENCE OF INITIAL CONSONANTS ON THE INTRINSIC PITCH OF HIGH AND LOW VOWELS IN THE MALAY DIALECT SPOKEN IN PATHUMTHANI PROVINCE, THAILAND}

\section{Phanintra Teeranon ${ }^{1}$}

\begin{abstract}
High vowels tend to have higher intrinsic $F_{0}$ (pitch) than low vowels (e.g. Lehiste, 1970; Whalen and Levitt, 1995). Higher intrinsic $F_{0}$ occurs on vowels which follow voiceless consonants, lower intrinsic $F_{0}$ occurs on vowels which follow voiced consonants. When high vowels follow voiced consonants and low vowels follow voiceless consonants, the voicing of initial consonants has been found to counterbalance the intrinsic $F_{0}$ value of high and low vowels. In other words, voiced consonants will lower $F_{0}$ values of high vowels, and voiceless consonants will raise $F_{0}$ values of low vowels to the extent that the average $F_{0}$ of these high vowels is actually lower than the average $F_{0}$ of the low vowels under examination (Clark and Yallop, 1990; House and Fairbanks, 1953; Lehiste, 1970; Lehiste and Peterson, 1961; Laver, 1994). To test whether this counterbalance finding is applicable to Southeast Asian languages, the $F_{0}$ values of high and low vowels following voiceless and voiced consonants were studied in a Malay dialect of the Austronesian language
\end{abstract}

${ }^{1} \mathrm{Ph} . \mathrm{D}$. candidate in Linguistics, Department of Linguistics, Faculty of Arts, Chulalongkorn University family spoken in Pathumthani Province, Thailand.

The data was collected from three male informants, aged 30-35. The Praat program was used for acoustic analysis. The findings revealed that the low vowel $/ \alpha /$ following a voiceless consonant tends to have a higher intrinsic $F_{0}$ value than the high vowels /i/ and /u/ when they follow voiced consonants. The results of the acoustical measurements of the $F_{0}$ values confirmed the counterbalance effect. These results also demonstrate that the influence of the voicing of initial consonants on the $F_{0}$ of vowels is greater than the influence of vowel height.

\section{Introduction}

Over many years of studying tonogenesis or tonal evolution theory, researchers have discovered two supposedly universal phenomena, which relate the auditory pitch with the rate of vocal fold vibration (fundamental frequency, $\mathrm{F}_{0}$ ) in the larynx.

First, with respect to the influence of initial consonants on the $\mathrm{F}_{0}$ of the following vowels, it has been shown that voiceless initial consonants (vl) increase $\mathrm{F}_{0}$ values and voiced initial consonants (vd) decrease $\mathrm{F}_{0}$ values, which apparently relate to auditory high pitch and low pitch, respectively. These findings were attested in a number of languages by many linguists (e.g., House and Fairbanks, 1953; Lehiste and Peterson, 1961; Lehiste, 1970; Hombert et al., 1979; Abramson and Erickson, 1992). This leads to the conclusion that voiceless consonants give birth to high tones and voiced consonants give birth to low tones.

Second, Whalen and Levitt (1995) have demonstrated a universal relationship 
between vowel height and fundamental frequency $\left(\mathrm{F}_{0}\right)$. For example, the high vowels $[\mathrm{i}]$ and $[\mathrm{u}]$ tend to have a higher $\mathrm{F}_{0}$ than the low vowel [a]. More than 30 languages representing 11 of the world's 29 language families (taken from David Crystal, 1987 in Whalen and Levitt, 1995: 349) have been found so far for this phenomenon.

A comparison of studies on intrinsic pitch phenomena in Indo-European and other language families with similar studies on language families in Southeast Asia has revealed that there are far fewer research reports dealing with the latter group. Southeast Asia is home to five distinct language families, namely Tai-Kadai, Hmong-Mien, Sino-Tibetan, Mon-Khmer, and Austronesian, languages in all of these families, except the Hmong-Mien, have been examined for the intrinsic $F_{0}$ phenomenon. Among the four language families, fewer studies have been found to deal with Austronesian languages. Malagasy is the only language that has been reported (Rakotofiringa, 1968, 1982, cited in Whalen and Levitt, 1995).

Though the application of different methodologies varies the size of the intrinsic pitch effect, all of the findings in Southeast Asian families showed that, as in European and other languages, the $\mathrm{F}_{0}$ of high vowels is higher than that of low vowels (Han, 1969; Mohr, 1971; Zee, 1980; Boonphan et al., 1982; Rakotofiringa, 1968, 1982, cited in Whalen and Levitt, 1995; Shi and Zhang, 1987; Svantesson, 1988; Rose, 1997; Watkins, 2002; Teeranon, 2005). Besides the experimental procedures, the difference between high and low vowels due to other factors was also examined by Whalen and Levitt (1995). Those factors were the front - back dimension of vowels, the size of the vowel inventory, the low end of a speaker's $\mathrm{F}_{0}$ range, the lexical tones and the sex of the speakers. The only factor that was found to affect the size of intrinsic pitch is the low end of a speaker's $F_{0}$ range. In tone languages, where pitch is manipulated for communicative function and vowels occur with the entire $\mathrm{F}_{0}$ range, intrinsic $\mathrm{F}_{0}$ persists. However, when vowels occur at the low end of the $F_{0}$ range, intrinsic $\mathrm{F}_{0}$ disappears (Whalen and Levitt, 1995).

Neither the influence of initial consonants nor the high-low dimension of vowels (or tongue height) seems to be under deliberate speech control; they are rather, automatic physiological mechanisms. Many proposals have been brought forward to explain these two phenomena. For the influence of initial consonants, the most convincing one is the mechanism of cricothyroid muscle of the larynx to stiffen the vocal folds for the voiceless state or to slacken the vocal folds for the voiced state (Hirose et al., 1972; Löfqvist et al., 1989). As for the influence of the high-low dimension of vowels, it has been suggested that, in the production of high vowels, vocal-fold tension is caused by the root of the tongue; moving the tongue root up to the palate raises the larynx and thus increases vocal-folds tension (Gregerson, 1976).

For many years, it has been argued that the voicing states of initial consonants change diachronically to give rise to tones (Matisoff, 1973). Some studies have also argued that differences in phonation type could be another cause of tone birth. In this research, the question is whether the high-low dimension of vowels is another important factor in tonogenesis and whether the universality of intrinsic pitch is corroborated by a particular Malay dialect. Therefore, this paper aims at analysing 1) 
intrinsic pitch of the high and low vowels in a Malay dialect, and 2) the influences of initial consonants on the intrinsic pitch of high and low vowels or the counterbalance effect. $^{2}$

In order to test the intrinsic-pitch phenomenon and the influence of initial consonants on the intrinsic $\mathrm{F}_{0}$, high and low vowels of the Malay dialect spoken in Pathumthani Province were analyzed by measuring the fundamental frequency values of vowels following voiceless and voiced stops.

\section{Method}

There are several methods to analyze test tokens which were drawn from the Malay dialect of Pathumthani ${ }^{3}$ spoken in Klong Bang Pho Village, Khu Bang Luang Subdistrict, Lad Lum Kaew District, Pathumthani Province. First, as this Malay dialect has a repertoire of six

\footnotetext{
2 To explain the counterbalance effect clearly, there is an example from Lehiste (1970: 73-74) who stated, "The influence of an initial consonant could counterbalance the influence of intrinsic pitch: the average of $/ \mathrm{kæ} /$ sequences was $171 \mathrm{~Hz}$, while that of /gi/ sequences amounted to $170 \mathrm{~Hz}$ " That is to say, generally the high vowel /i/ has higher $\mathrm{F}_{0}$ values than the low vowels $/ \mathfrak{x} /$ however when the high vowel / $\mathbf{i}$ / is preceded by voiced initial consonants as in /gi/ and the low vowel $/ \mathfrak{x} /$ is preceded by voiceless initial consonants, as in $/ \mathrm{kæ} /$, then the high vowel /i/ has a lower $\mathrm{F}_{0}$ value than the low vowel $/ æ /$.

${ }^{3}$ In Pathumthani Province, Thailand, dialects of Malay are mainly spoken in six communities: Klong Bang Pho, Tha-it, Klongnung, Bang Bua Thong, Krathumrai, and Sai Kong Din. The informants for this study are from one of the twelve villages of Klong Bang Pho.
}

monophthongal vowels /i, u, ə, a, $\varepsilon, \mathrm{o} /$ with no vowel-length distinction, the three vowels representing high and low vowels selected in this study were $/ \mathrm{i} /, / \mathrm{u} / \mathrm{and} / \mathrm{a} / \mathrm{I}$ restricted the analysis to these three vowels because they were used in most of the previous research. Moreover, the vowel /a/, which should be compared with the vowel /a/, occurs only in unstressed syllables. Second, a number of words were selected from dictionaries, research reports, and other relevant documents. Based on the assumption that point of articulation has no effect on the $\mathrm{F}_{0}$ of vowels (Maddieson, 1984; L-Thongkum, 1992), four test tokens were selected for each of the vowels $/ \mathrm{i} /, / \mathrm{a} /$ and $/ \mathrm{u} /$, preceded by consonants with the same manner of articulation, i.e., voiceless consonants $(/ \mathrm{p} /, / \mathrm{t} /, / \mathrm{k} /)$ and voiced consonants $(/ \mathrm{b} /, / \mathrm{d} /, / \mathrm{g} /)$. For each voicing state four words were chosen to appear before each vowel, as follows: 


\begin{tabular}{|c|c|c|}
\hline \multicolumn{3}{|c|}{ Voiceless initials } \\
\hline$-\mathrm{i}-$ & $-a-$ & $-\mathrm{u}-$ \\
\hline Papi 'fire' & Pipa 'daughter-in-law' & sapu 'to sweep' \\
\hline hati 'heart' & bata 'pillow' & satu 'one' \\
\hline mati 'to die' & tika 'mat' & mutu 'motorcycle' \\
\hline kaki 'foot' & sika 'bicycle' & hatu 'ghost' \\
\hline \multicolumn{3}{|c|}{ Voiced initials } \\
\hline$-\mathrm{i}-$ & $-a-$ & $-\mathrm{u}-$ \\
\hline hubi 'potato' & təba 'thick' & dəbu 'dust' \\
\hline babi ‘pig’ & kuba 'buffalo' & labu 'pumpkin' \\
\hline fadi 'to be' & kəda 'market' & budu 'a kind of fish sauce' \\
\hline pagi 'morning' & pəda 'stomach' & madu 'bee' \\
\hline
\end{tabular}

Then, before recording the speech, every word in the list was carefully checked with a Malay informant. Third, three male informants aged $30-35$ were chosen. The informants were then asked to pronounce each test word in isolation five times. The first three words were selected in order to avoid any intonation effects that might occur. The number of total test tokens was 162 (3 informants x 2 initial voicing states $\mathrm{x} 3$ vowels $\mathrm{x} 3$ words $\mathrm{x} 3$ repetitions). The recordings were made using a Sony recorder. The Praat program, version 4.2.05 was used to analyze the fundamental frequencies of the isolated words.

To assess the perturbation from initial consonants, the fundamental frequency was measured at the onset, the mid-point, and the offset of each vowel. The mean values of the vowels, /i/ (high), /a/ (low), and /u/ (high), were analyzed statistically using a $t$ test and analysis of variance (ANOVA) with a 95\% level of confidence. Line graphs were drawn using Microsoft Excel.

\section{Results \\ Intrinsic $F_{0}$ of vowels}

Intrinsic $F_{0}$ of vowels following voiceless consonants

The data show that the high vowels $/ \mathrm{i}, \mathrm{u} /$ had a higher $\mathrm{F}_{0}$ than the low vowel $/ \mathrm{a} /$ at the onset, the mid point, and the offset (Table 1 and Figure 1). The average intrinsic $\mathrm{F}_{0}$ difference amounted to $0.92 \mathrm{~Hz}, 5.87 \mathrm{~Hz}$, and $3.71 \mathrm{~Hz}$, respectively. The overall means show the same result; their intrinsic $\mathrm{F}_{0}$ difference amounted to $3.51 \mathrm{~Hz}$. However, the $t$-test $(\alpha=.05)$ showed no significant difference for the onset $(p$ $=.792)$, the mid-point $(\mathrm{p}=.095)$, the offset $(\mathrm{p}=.336)$, or the overall means $(\mathrm{p}=.239)$. 
Table 1 Intrinsic $\mathrm{F}_{0}(\mathrm{~Hz})$ of high and low vowels following voiceless consonants measured at the onset, the mid-point, and the offset together with and overall means

\begin{tabular}{|l|c|c|c|c|c|}
\hline \multicolumn{1}{|c|}{ vowels } & $\mathrm{i}$ & $\mathrm{a}$ & $\mathrm{u}$ & $\begin{array}{c}\text { mean } \\
\text { difference }\end{array}$ & sig $^{4}$ \\
\hline onset & 147.96 & 145.49 & 144.86 & 0.92 & - \\
\hline mid-point & 134.14 & 130.23 & 138.06 & 5.87 & - \\
\hline offset & 120.12 & 119.27 & 125.84 & 3.71 & - \\
\hline overall means & 134.08 & 131.66 & 136.25 & 3.51 & - \\
\hline
\end{tabular}

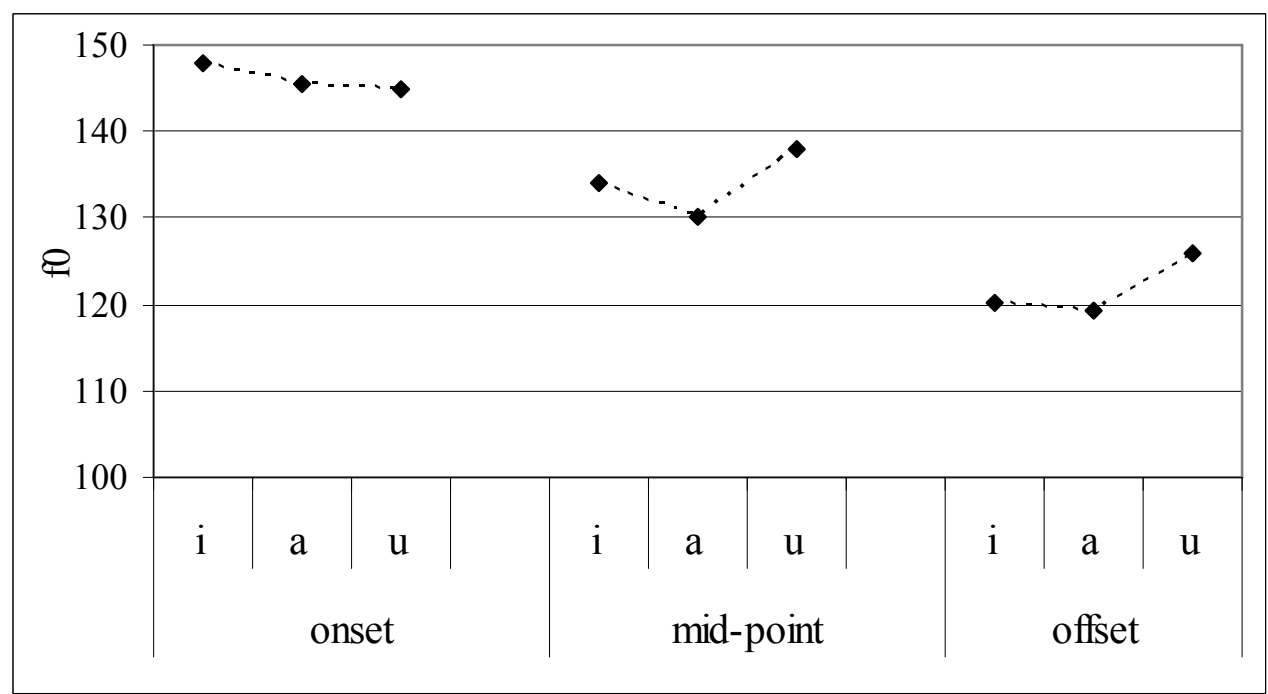

Figure 1 Intrinsic $\mathrm{F}_{0}(\mathrm{~Hz})$ of high and low vowels following voiceless consonants measured at the onset, the mid-point, and the offset

\footnotetext{
${ }^{4}$ In this last column ( $\mathrm{sig}$ );

- represents insignificant difference

* represents significant difference
} 
The significance of these differences was examined by means of an ANOVA. The difference at the mid-point was significantly $(\mathrm{p}=.011)$ greater than at the onset, but it was insignificantly $(p=.261)$ greater than at the offset. The difference in intrinsic $\mathrm{F}_{0}$ at the onset and the offset was also not significant $(\mathrm{p}=.149)$.
Intrinsic $F_{0}$ of vowels following voiced consonants

The findings show that the high vowels /i, $\mathrm{u} / \mathrm{had}$ higher $\mathrm{F}_{0}$ than the low vowel /a/ at the onset, the mid point, and the offset (Table 2 and Figure 2). The overall means show the same result; its size of intrinsic $\mathrm{F}_{0}$ amounted to $5.68 \mathrm{~Hz}$. The t-test $(\alpha=.05)$ shows significant difference for the mid point $(\mathrm{p}=.009)$ and the overall means $(\mathrm{p}$ $=.044$ ), but shows no significant difference at the onset $(p=.526)$ or the offset $(p$ $=.178)$.

Table 2 Intrinsic $\mathrm{F}_{0}(\mathrm{~Hz})$ of high and low vowels following voiced consonants measured at the onset, the mid-point, and the offset, together with overall means

\begin{tabular}{|l|c|c|c|c|c|}
\hline \multicolumn{1}{|c|}{ vowels } & $\mathrm{i}$ & $\mathrm{a}$ & $\mathrm{u}$ & $\begin{array}{c}\text { mean } \\
\text { difference }\end{array}$ & sig \\
\hline onset & 134.65 & 133.63 & 136.87 & 2.13 & - \\
\hline mid-point & 133.07 & 122.59 & 132.62 & 10.26 & $*$ \\
\hline offset & 114.88 & 110.60 & 115.61 & 4.65 & - \\
\hline overall means & 127.54 & 122.28 & 128.37 & 5.68 & $*$ \\
\hline
\end{tabular}

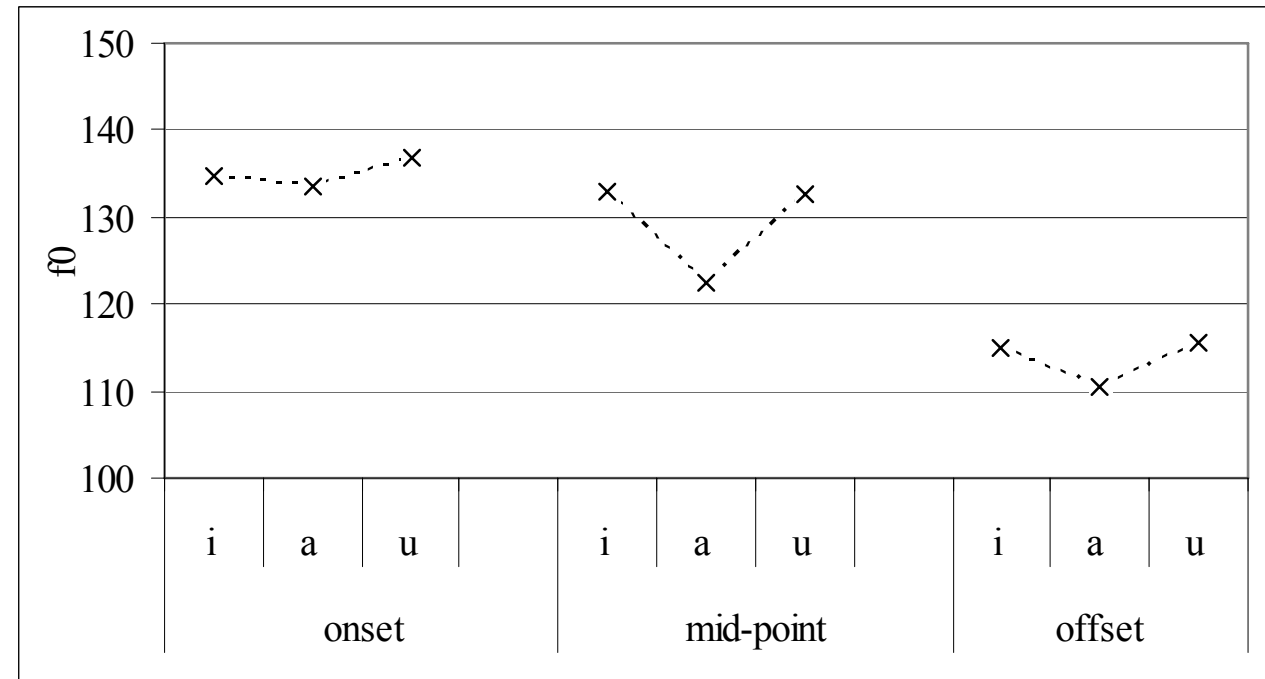

Figure 2 Intrinsic $\mathrm{F}_{0}$ value $(\mathrm{Hz})$ of high and low vowels following voiced consonants measured at the onset, the mid-point, and the offset 
The difference in intrinsic $\mathrm{F}_{0}$ was greatest when measured at the mid-point $(10.26 \mathrm{~Hz})$ comparing to the offset $(4.65 \mathrm{~Hz})$ and the onset $(2.13 \mathrm{~Hz})$, respectively. The significance of these differences was examined by using ANOVAs. The difference at the mid point is significantly greater than at the onset $(p=.000)$ and at the offset $(p=.005)$, but the difference at the onset and the offset was not significantly different $(p=.202)$.

Intrinsic $F_{0}$ of vowels following voiceless and voiced consonants

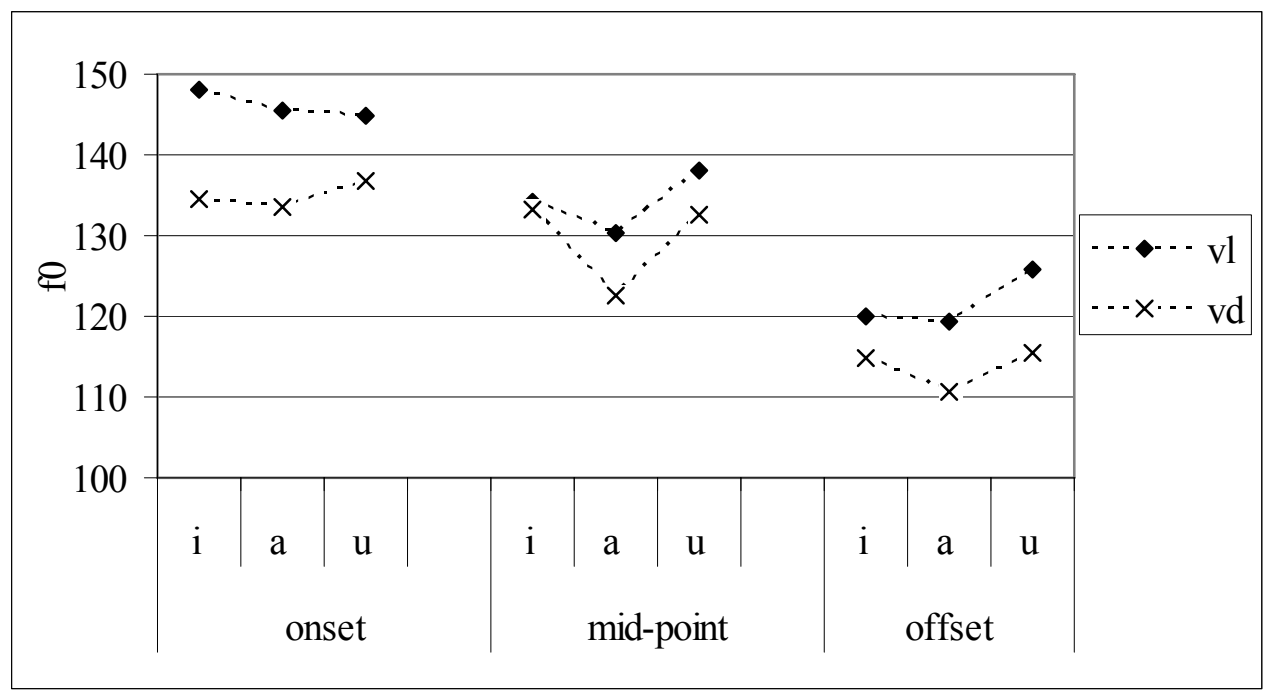

Figure 3 Intrinsic $\mathrm{F}_{0}(\mathrm{~Hz})$ of high and low vowels following voiceless and voiced consonants measured at the onset, the mid-point, and the offset

When comparing the $\mathrm{F}_{0}$ values of high and low vowels following voiceless and voiced initial stops (Table 1 and 2 and Figure 3), the findings show higher intrinsic $\mathrm{F}_{0}$ following voiceless consonants and lower intrinsic $\mathrm{F}_{0}$ following voiced consonants.
The $t$-test $(\alpha=.05)$ shows that intrinsic $\mathrm{F}_{0}$ on the vowels following voiceless consonants and voiced consonants, showed no significant difference at the onset $(\mathrm{p}$ $=.628)$ or at the offset $(p=.574)$. However, at the mid-point, the difference was significant $(p=.005)$. 
Table 3 Overall means of intrinsic $\mathrm{F}_{0}(\mathrm{~Hz})$ following voiceless and voiced consonants

\begin{tabular}{|l|c|c|c|c|}
\hline $\begin{array}{l}\text { initial } \\
\text { consonants }\end{array}$ & $\mathrm{i}$ & $\mathrm{a}$ & $\mathrm{u}$ & $\begin{array}{c}\text { mean } \\
\text { difference }\end{array}$ \\
\hline voiceless & 134.08 & 131.66 & 136.25 & 3.51 \\
\hline voiced & 127.54 & 122.28 & 128.37 & 5.68 \\
\hline
\end{tabular}

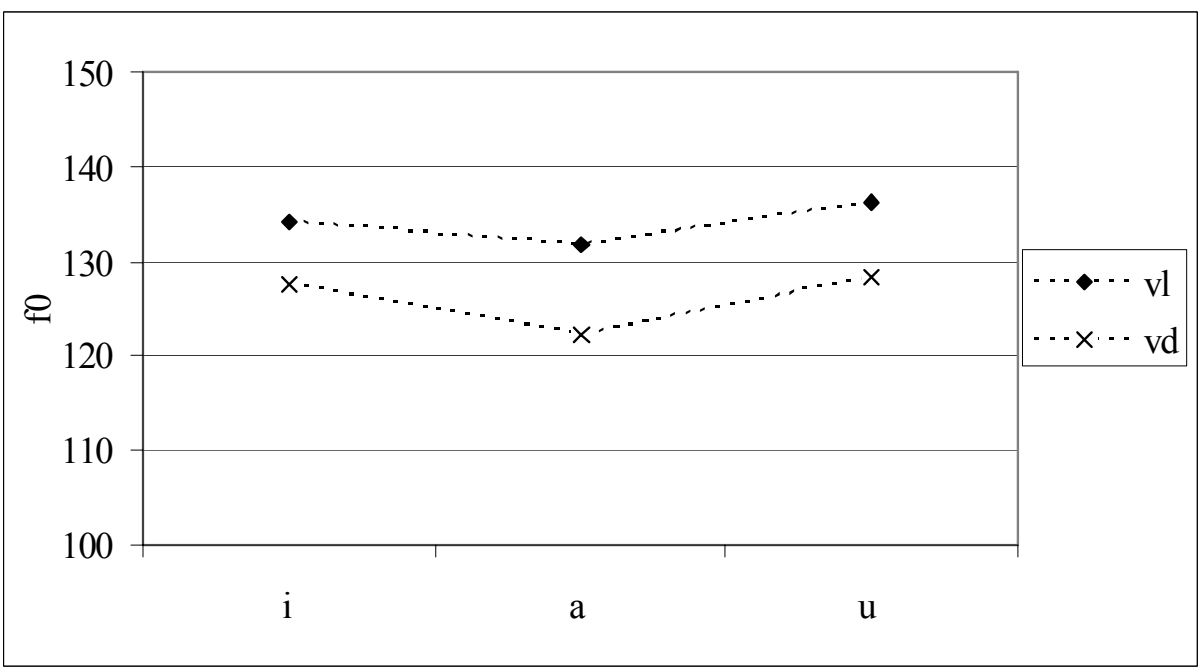

Figure 4 Overall means of intrinsic $\mathrm{F}_{0}(\mathrm{~Hz})$ following voiceless and voiced consonants

The overall means of intrinsic $\mathrm{F}_{0}$ are higher on vowels following voiceless consonants than on vowels following voiced consonants (Table 3 and Figure 4). The intrinsic $\mathrm{F}_{0}$ following voiced consonants was significantly $(\mathrm{p}=.032)$ higher than the $\mathrm{F}_{0}$ following voiced consonants.

\section{The Influence of initial consonants on intrinsic pitch}

The findings show that when high vowels, /i, $\mathrm{u} /$, follow voiced consonants, they have a lower $F_{0}$ at the onset than the low vowel /a/ following voiceless consonants (Table 4 and Figure 5). ANOVAs showed that the intrinsic $\mathrm{F}_{0}$ difference was $9.73 \mathrm{~Hz}$, which is significant $(\mathrm{p}=.003)$.

A different result was found at the midpoint, where high vowels following voiced consonants did not show significantly $(p$ $=.462$ ) higher $\mathrm{F}_{0}$ values than those of the low vowel. The intrinsic $\mathrm{F}_{0}$ difference was $2.62 \mathrm{~Hz}$.

A similar result was found at the offset. High vowels following voiced consonants showed a significantly $(p=.274)$ lower $F_{0}$ than low vowel in the same environment. The difference was $4.03 \mathrm{~Hz}$. 
The Influence of Initial Consonants on the Intrinsic Pitch of High and Low Vowels

Table 4 Intrinsic $\mathrm{F}_{0}(\mathrm{~Hz})$ of high vowels following voiced initial consonants $\left(-\mathrm{C}_{\mathrm{vd}}-\right)$ and low vowels following voiceless initial consonants $\left(-\mathrm{C}_{\mathrm{vl}}-\right)$ measured at the onset, the midpoint, and the offset

\begin{tabular}{|l|c|c|c|c|c|}
\hline $\begin{array}{l}\text { vowels } \\
\text { position }\end{array}$ & $-\mathrm{C}_{\mathrm{vd}}-\mathrm{i}$ & $-\mathrm{C}_{\mathrm{v}}-\mathrm{a}$ & $-\mathrm{C}_{\mathrm{vd}}-\mathrm{u}$ & $\begin{array}{c}\text { mean } \\
\text { difference }\end{array}$ & sig \\
\hline onset & 134.65 & 145.49 & 136.87 & -9.73 & $*$ \\
\hline mid & 133.07 & 130.23 & 132.62 & 2.62 & - \\
\hline offset & 114.88 & 119.27 & 115.61 & -4.03 & - \\
\hline overall means & 127.53 & 131.66 & 128.45 & -3.67 & - \\
\hline
\end{tabular}

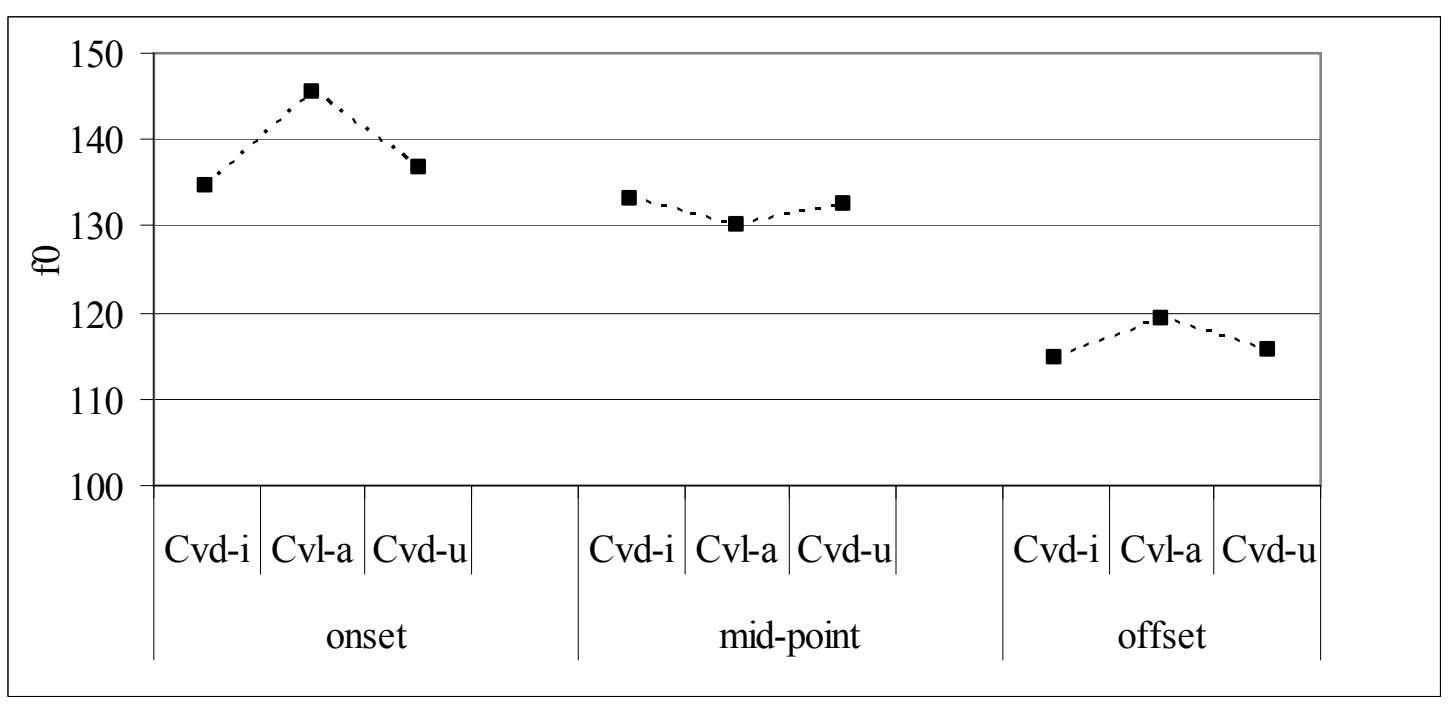

Figure 5 Intrinsic $\mathrm{F}_{0}(\mathrm{~Hz})$ of high vowels following voiced consonants and low vowels following voiceless initial consonants, measured at the onset, the mid-point, and the offset

\footnotetext{
${ }^{5}$ Minus symbol (-) in the column represents lower $F_{0}$ values of high vowels following voiced consonants when comparing to that of low vowels following voiceless consonants.
} 
At the mid-point, the $\mathrm{F}_{0}$ values of $/-\mathrm{C}_{\mathrm{vl}}-\mathrm{a} /$ were not higher than those of $/-\mathrm{C}_{\mathrm{vd}}-\mathrm{i} /$ and $/-\mathrm{C}_{\mathrm{vd}}-\mathrm{u} /$, as they were found to be at in the onset and the offset. This may be due to vowels exhibiting a stronger intrinsic-pitch effect at the mid-point than at the onset or the offset (see 4.1.1 and 4.1.2).
ANOVAs showed that consonant type had a greater effect on the intrinsic $F_{0}$ at the onset than at the mid point $(\mathrm{p}=.000)$ and the offset $(p=.003)$. Likewise, consonant type had a greater effect on the intrinsic $\mathrm{F}_{0}$ at the mid-point than at the offset; this was also significant $(\mathrm{p}=.001)$.

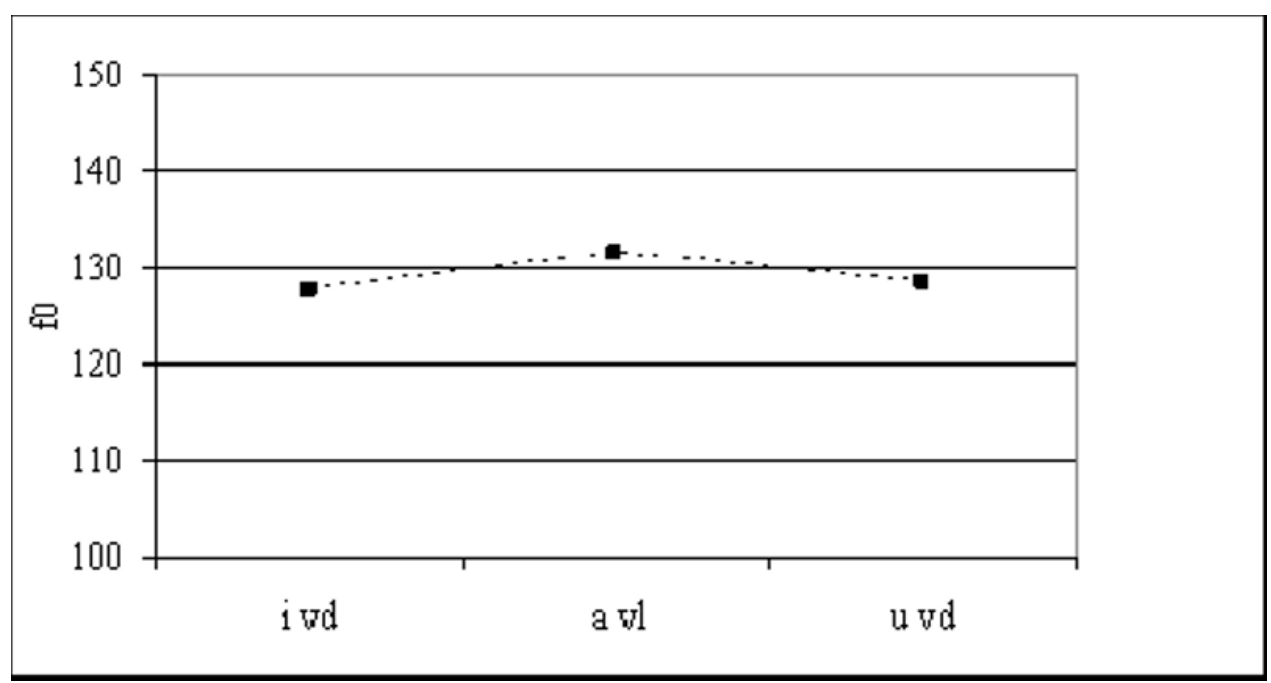

Figure 6 Intrinsic $\mathrm{F}_{0}(\mathrm{~Hz})$ of high vowels following voiced consonants and low vowels following voiceless consonants

The mean difference of the overall average intrinsic $\mathrm{F}_{0}$ values of high vowels following voiced consonants and the low vowel /a/ following voiceless consonants at the onset, the mid-point, and the offset was $3.67 \mathrm{~Hz}$, which was not significant $(\mathrm{p}=.256)$.

\section{Discussion and Conclusion}

In the Malay dialect spoken in Pathumthani Province, Thailand, there is a tendency for high vowels to have higher intrinsic $F_{0}$ values than low vowels. These findings corroborate the theory of intrinsic vowel pitch developed by Whalen and Levitt (1995), Connell (2002), Whalen et al. (1999).
Compared with the $15.3 \mathrm{~Hz}$ difference in intrinsic $\mathrm{F}_{0}$ across the language of the Malay dialect of Pathumthani Province and with the 13.9 $\mathrm{Hz}$ difference in intrinsic $\mathrm{F}_{0}$ for all male speakers determined by Whalen and Levitt (1995), the findings here show much smaller values. However, when compared with 1.5 $\mathrm{Hz}$ (Rakotofiringa, 1968, cited in Whalen and Levitt, 1995) and $4.5 \mathrm{~Hz}$ (Rakotofiringa, 1982, cited in Whalen and Levitt, 1995) for Malagasy of the Austronesian language family, these findings are much closer (3.51 $\mathrm{Hz}$ to $5.68 \mathrm{~Hz}$ ). 
When measuring the intrinsic pitch of vowels following voiceless consonants at the onset of the vowels, the $\mathrm{F}_{0}$ of $/ \mathrm{u} /$ is a bit lower than that of $/ \mathrm{a} /$, which does not seem to support the intrinsic pitch theory. In some previous studies, the $\mathrm{F}_{0}$ of $/ \mathrm{u} /$ has been lower than that of /a/ (Shi and Zhang, 1987; Zee, 1980), indicating that the phenomenon is not absolutely universal.

Voiceless and voiced consonants can counterbalance the effect of intrinsic pitch in that voiced initial consonants can lower the intrinsic pitch of high vowels and voiceless initial consonants can raise the intrinsic pitch of low vowels. This finding supports the counterbalance effect (House and Fairbanks, 1953; Lehiste, 1970; Lehiste and Peterson, 1961; Laver, 1994).

Statistical analysis (ANOVA) clearly shows that, at the onset of vowels, the effect of initial-consonant voicing on intrinsic pitch is significantly greater than at the mid-point or at the offset. This corroborates the universality of the influence of initial voicing upon the onset of vowels in the Tonogenesis Theory (Gandour, 1974; Hombert et al., 1979; Maddieson, 1984; L-Thongkum, 1992; Abramson, 2004).

The corroboration of the counterbalance effect suggests that the influence of intrinsic pitch on the $F_{0}$ value of vowels is less than the influence of the voicing states of initial consonants. In other words, the voicing states of initial consonants seem to be a more important factor for tonogenesis, but changing in high-low dimensions of the tongue will not be an important factor for phonological pitch. Thus, the intrinsic $\mathrm{F}_{0}$ differences caused by vowel height could not have given rise to the birth of tone in the same way that voicing states of initial consonants apparently have as stated earlier by Hombert, 1977; Hombert et al., 1979; and Fischer-J2rgensen, 1990.

\section{Acknowledgements}

I would like to express my deep gratitude to Prof. Theraphan Luangthongkum, Prof. Arthur S. Abramson and Dr. Rungpat Ruengpitaya for their comments and suggestions.

I am also thankful to local authorities and my informants in Klong Bang Pho Village, Khu Bang Luang Subdistrict, Lad Lum Kaew District, Pathumthani Province.

\section{References}

Abramson, A. S. 2004. The plausibility of phonetic explanations of tonogenesis. In G. Fant, H. Fujisaki, J. Cao, and Y. Xu (eds.), From Traditional Phonology to Modern Speech Processing: Festchrift for Professor Wu Zongji's 95 Birthday, 17-29. Beijing: Foreign Language Teaching and Research Press. Abramson, A. S. and D. Erickson. 1992. Tone split and voicing shifts in Thai: Phonetic plausibility. Proceedings of the $3^{\text {rd }}$ International Symposium on Language and Linguistics I: 1-15. Boonphan, C., P. Deephungton, and S. Svetamalaya. 1982. Fundamental frequency of [i], [u], [a] in Standard Thai. Science of Language 2, 7-20. [in Thai]

Clark, J. and C. Yallop. 1990. An introduction to Phonetics and Phonology. Oxford: Basil Blackwell. 
Connell, B. 2002. Tone languages and the universality of intrinsic $\mathrm{F}_{0}$ : evidence from Africa. Journal of Phonetics 30, 101-29.

Crystal, D. 1987. The Cambridge encyclopedia of language. Cambridge: University Press.

Fischer-J2rgenson, E. 1990. Intrinsic $\mathrm{F}_{0}$ in tense and lax vowels with special reference to German. Phonetica 47, 99-140.

Gandour, J. T. 1974. Consonant types and tone in Siamese. Journal of Phonetics 2: 337-50.

Gregerson, K. L. 1976. Tongue-root and register in Mon-Khmer. In P.N. Jenner et al. (eds.), Austroasiatic Studies 1, 323-66. Honolulu: The University Press of Hawaii.

Hirose, H., L. Lisker, A. Abramson and T. Gay. 1972. The activity of the intrinsic laryngeal muscles in voicing control: an electromyographic study. Phonetica 25: 140-64.

Han, M. S. 1969. Vietnamese tones. Studies in the Phonology of Asian Languages 8. Los Angeles: University of Southern California.

Hombert, Jean-Marie. 1977. Development of tones from vowel height. Journal of Phonetics 5, 9-16.

Hombert, J.-M., J.J. Ohala, and W.G. Ewan. 1979. Phonetic explanations for the development of tones. Language 55, 37-58.

House, A. S. and G. Fairbanks. 1953. The influence of consonant environment upon the secondary acoustical characteristics of vowels. Journal of the Acoustical Society of America 25: 105-13.

Laver, J. 1994. Principles of Phonetics. Cambridge: University Press.

Lehiste, I. 1970. Suprasegmentals. Massachusetts: MIT Press.
Lehiste, I. and G. E. Peterson. 1961. Some basic considerations in the analysis of intonation. Journal of Acoustical Society of America 33: 419-25.

Löfqvist, A., T. Baer, N. McGarr and R. S. Story. 1989. The cricothyroid muscle in voicing control. Journal of the Acoustical Society of America 85: 1314-1321.

L-Thongkum, T. 1992. The raising and lowering of pitch caused by a voicing distinction in sonorants (nasals and approximants): An epidemic disease in SEA languages. Proceeding of the $3^{r d}$ International Symposium on Language and Linguistics, January 1992, Bangkok, 10791087.

Maddieson, I. 1984. The effcts on f0 of a voicing distinction in sonorants and their implication for a theory of tonogenesis. Journal of Phonetics 12, 9-15.

Mohr, B. 1971. Intrinsic variations in the speech signal. Phonetica 23, 6593.

Rakotofiringa, H. 1968. Contributions à l'étude de la phonétique malgache II: hauteur, durée et intensité vocaliques éfficacés. Université de Grenoble.

Rakotofiringa, H. 1982. L'accent et les unites phoniques elementaires de base en malgache-merina. Lille: Atelier National de Reproduction des Theses, Université de Lille. 
Rose, P. 1997. A Seven-Tone Dialect in Southern Thai with Super-High: Pakphanang Tonal Acoustics and Physiological Inferences. In Arthur S. Abramson (ed.), Southeast Asian Linguistics Studies in Honour of Vichin Panupong. Bangkok: Chulalongkorn Printing House.

Shi, B., and J. Zhang. 1987. Vowel intrinsic pitch in standard Chinese. In Proceedings XIth International Congress of Phonetic Science 1, 142-45. Tallinn, Estonia: Academy of Sciences of the Estonian SSR.

Svantesson, J. 1988. Voiceless stops and $\mathrm{F}_{0}$ in Kammu. Lund University Department of Linguistic Working Papers 34, 116-19.

Teeranon, P. 2005. Intrinsic pitch and intrinsic length in Waic languages. Seminar on Ph.D. Golden Jubilee Fund (Social Sciences and Humanities), The Thailand Research Fund, 7 January 2005, Institute of Language and Culture for Rural Development, Mahidol University, Nakhon Pathom, Thailand. [in Thai]

Watkins, J. 2002. The phonetics of Wa: experimental phonetics, phonology, orthography and sociolinguistics. Canberra: Research School of Pacific and Asian Studies, The Australian National University.

Whalen, D. H. and A. G. Levitt. 1995. The universality of intrinsic $\mathrm{F}_{0}$ of vowels. Journal of Phonetics 23, 349-66.
Whalen, D. H., B. Gick and P. S. Lesourd. 1999. Intrinsic $\mathrm{F}_{0}$ in Passamaquoddy vowels. In David Pentland (ed.), Papers from the $30^{\text {th }}$ Algonquian Conference, 417 28. Winnipeg: University of Manitoba.

Zee, E. 1980. Tone and vowel quality. Journal of Phonetics 8, 247-58. 